\title{
Perceções de estudantes universitários chineses sobre o ensino-aprendizagem de português língua estrangeira - Iniciantes
}

\section{Chinese University Students' Perceptions on Teaching and Learning of Portuguese as a Foreign Language - Beginners}

\author{
Ana Margarida Belém Nunes [ananunes@umac.mo] \\ 澳门大学, Universidade de Macau, China \\ Francisco Pelicano Antunes [fantunes@umac.mo] \\ 澳门大学, Universidade de Macau, China
}

\begin{abstract}
RESUMO
O processo de ensino-aprendizagem de uma segunda língua é complexo e largamente influenciado pelas perceções do professor e do estudante, com impacto no sucesso das aprendizagens. Compreender a identidade cultural do aprendente, assim como as suas perspetivas quanto ao ensino-aprendizagem de uma língua estrangeira e a sua recetividade às atividades propostas é muito importante para assegurar uma aprendizagem bem sucedida e evitar conflitos entre a cultura de ensino do aprendente e o seu contacto com novas tendências pedagógicas. Este trabalho procura conhecer as perceções do aprendente chinês de português língua estrangeira (PLE), cujo percurso pedagógico está profundamente formatado pelos métodos tradicionais. Recorrendo à investigação baseada em inquérito (survey), os resultados apontam para um perfil de aluno profundamente moldado pelo seu background cultural, mas também prático e recetivo à ideia de mudança
\end{abstract}

\section{Palavras-Chave}

Aprendente chinês; cultura de ensino-aprendizagem; português língua estrangeira; perceções do aprendente

\begin{abstract}
Second language teaching and learning is a complex process largely influenced by the perceptions of the teacher and the student, with an evident impact on the success of the education. Understanding the cultural identity of the learner and their perceptions of the foreign language teaching-learning process as well as their openness to the proposed activities is very important to ensure successful learning and to avoid conflicts between the learner's culture and new pedagogical tendencies. The present work seeks to better understand the perceptions that the Chinese learner of Portuguese as a Foreign Language (PFL) has. Using survey-based research, the results point out to a student that is deeply molded by its cultural background but also very active and receptive to the novelty.
\end{abstract}

\section{KEYWORDS}

Chinese learner; teaching and learning traditions; Portuguese as a foreign language; student perceptions.

RECEBIDO 2019-12-01; ACEITE 2020-02-18 


\section{Introdução}

O interesse crescente pelo português na China, nas últimas décadas, tem-se concretizado no crescimento da grande procura deste idioma por aprendentes chineses. Atualmente a aprendizagem de português envolve várias instituições de ensino, públicas e privadas, e a licenciatura em língua portuguesa é oferecida por quase 40 universidades da República Popular da China (RPC) a mais de três mil estudantes. O enorme investimento económico da China em países lusófonos, sobretudo em Angola e no Brasil, tem contribuído significativamente para o aumento da procura do português que é visto, cada vez mais, como uma boa aposta profissional, com garantias de colocação no mercado de trabalho e oferecendo perspetivas de empregos bem remunerados em diversos setores como a banca, a diplomacia, a tradução, os negócios, e até mesmo o ensino (Belchior 2011).

Esta enorme apetência pela aprendizagem da língua lusa na RPC tem vindo, por um lado, a evidenciar a grande escassez de professores nativos e, por outro, a suscitar o aumento da cooperação entre estabelecimentos chineses de ensino superior e congéneres lusófonos - nomeadamente de Portugal e do Brasil - visando sobretudo a aprendizagem de português língua estrangeira em contextos de imersão linguística.

Macau - onde há também largas centenas de aprendentes chineses de PLE matriculados nas diferentes instituições educativas de nível superior e a confluência das culturas oriental e ocidental é historicamente intensa - constitui, por isso mesmo, um local privilegiado para estudar e compreender de forma mais aprofundada a dinâmica das interações entre conceções diferentes de ensino e de aprendizagem. Neste contexto sociolinguístico, e visando o sucesso das aprendizagens, torna-se importante o conhecimento da cultura tradicional de ensino-aprendizagem na China por parte dos professores ocidentais de línguas estrangeiras lecionando aprendentes chineses (Tang e Absalom 1998), que é indelevelmente marcada pelo arquétipo confucionista (Li 2001).

Os estudantes chineses efetuam por norma um percurso de ensino muito centrado no docente e numa aprendizagem passiva. Por isso, num contexto pedagógico diferente do tradicional, como acontece quando têm um professor nativo de língua estrangeira (LE), estranham os métodos de ensino e os novos estilos de aprendizagem (Oxford 2003). Por outro lado, o docente de uma LE que não tem experiência de ensino a alunos de matriz cultural confuciana tenderá a olhá-los à luz da sua própria cultura, podendo facilmente ficar com a opinião de que eles são passivos, acomodados a uma pedagogia tradicional e resistentes a mudanças.

\section{O presente estudo e seus objetivos}

Um dos níveis para compreender o ensino-aprendizagem, nota Biggs (1996), é o da análise das caraterísticas dos aprendentes, e Chan (2008) considera que tem havido pouca investigação sobre a aprendizagem (e o ensino) de chineses face às novas metas e desafios educativos. Relativamente a esta realidade, Tait (2011-2012) considera que a representação do aprendente chinês deve ser entendida através de estudos empíricos, no âmbito dos quais este trabalho de investigação se enquadra como modesto contributo.

O presente estudo centra-se nas perceções dos aprendentes chineses de PLE sobre o ensino e a aprendizagem, procurando entender não apenas as conceções culturais que modelaram a sua 
vida escolar, mas também o modo como reagem a um ambiente educativo diferente daquele em que foram escolarizados. Neste âmbito, e tendo presente um percurso de ensino-aprendizagem orientado pela continuidade de práticas pedagógicas seculares que em dado momento é confrontado com uma situação de mudança (novo contexto de aprendizagem), é particularmente interessante perceber como é que os aprendentes chineses se adaptam a novos desafios pedagógicos e, sobretudo, a um contexto comunicativo de aprendizagem que propõe o desenvolvimento de uma competência comunicativa na língua-alvo através do seu uso, de situações autênticas de interação verbal, da integração das diferentes competências linguísticas (Richards e Rodgers 2001), de jogos de simulação ou dramatizações; que atribui ao professor, primeiramente, a função de facilitar a comunicação e, secundariamente, a correção de erros (Celce-Murcia 2014); que encara o aluno como o foco da aprendizagem e estabelece uma relação ensinante-aprendente de tipo horizontal, mais informal e igualitária (Lee 2007).

Assim, este estudo tem como objetivos:

i. o conhecimento das conceções de ensino-aprendizagem de estudantes chineses no início da aprendizagem de português língua estrangeira;

ii. a compreensão do modo como eles se adaptam a um novo contexto de ensino comunicativo, bem diferente das práticas pedagógicas tradicionais que marcaram todo o seu percurso escolar.

Neste trabalho participaram 47 estudantes de $1 .^{\circ}$ ano (1. ${ }^{\circ}$ semestre) da licenciatura em Estudos Portugueses da Universidade de Macau (UMAC), correspondendo a 70\% da taxa de amostragem em relação à população-alvo, provenientes de escolas do ensino secundário da RPC e de Macau, com idades compreendidas entre os 18 e os 19 anos. Aquando da colheita de dados, o currículo do $1 .^{\circ}$ ano da licenciatura oferecida pelo Departamento de Português da UMAC era o seguinte:

- Oral Comprehension and Production - 6 horas por semana, lecionadas por um professor português;

- Written Comprehension and Production - 6 horas semanais, a cargo de um docente chinês;

- Language and Lusophone Culture - 3 horas semanais, lecionadas por um professor português.

Este estudo partiu do pressuposto de que na fase inicial da aprendizagem estes estudantes revelam resistência à mudança de paradigma educativo e estão mais arreigados à cultura chinesa tradicional de ensino, demonstrando por isso menos abertura ao desenvolvimento da competência comunicativa.

Como se constata, os aprendentes que participaram nesta investigação tiveram 2 docentes portugueses e 1 chinês, facto que comprova a forte exposição destes estudantes, a padrões de ensino distintos dos que moldaram a sua cultura tradicional de ensino-aprendizagem. 


\section{Metodologia}

Um dos instrumentos de recolha de dados utilizado na presente investigação foi um questionário constituído por 3 perguntas abertas (em português e chinês) incidindo sobre os tópicos de trabalho que foram posteriormente objecto de uma análise de conteúdo, de acordo com a frequência da indicação de ideias comuns. As questões eram as seguintes:

1. Para si, o que é um bom professor de língua estrangeira?

2. Em sua opinião, como deve ser um bom aluno de língua estrangeira?

3. Quais são as condições ideais para aprender uma língua estrangeira?

A análise das perspetivas dos aprendentes foi feita com base no conteúdo das respostas abertas obtidas e os resultados, apresentados em gráficos (Figuras 1. a 3.), foram analisados a partir da frequência da indicação de ideias compartilhadas.

Com o mesmo objetivo foi também construída uma escala de Likert com 35 asserções cobrindo uma série de tópicos relacionados com o ensino e a aprendizagem de PLE (Figuras 4. a 9.), nomeadamente o papel do professor, os materiais didáticos, as atividades e interações desenvolvidas nas aulas, a utilização da língua-alvo e do idioma materno, abordagens e métodos de ensino, estilos de ensino e de aprendizagem, tendo todas as afirmações sido traduzidas para chinês (língua materna dos aprendentes) de modo a assegurar que os participantes compreendiam o significado delas. O inquérito foi aplicado entre 3 e 4/9/2018, após obtenção de consentimento prévio.

Antes da implementação do inquérito foi testada a sua adequação aos objetivos da investigação e a clareza das afirmações através da aplicação de um estudo piloto, ou pré-teste, a um pequeno número de respondentes.

\section{O paradigma chinês de ensino-aprendizagem}

Os métodos usuais de ensino de línguas estrangeiras na China estão focados no conhecimento da estrutura da língua-alvo, recorrem à explicitação das regras gramaticais, à tradução literal e à explicação do significado das palavras isoladas e descontextualizadas (Dzau 1990), sem a preocupação do desenvolvimento da competência comunicativa. O pressuposto pedagógico subjacente a este modelo é o de que é importante conhecer a gramática e o vocabulário da LE e de que a proficiência linguística progride na mesma proporção do número de palavras ou de textos conhecidos exaustivamente. O ensino é expositivo e centrado no professor que é visto, a par do manual, como a fonte de conhecimentos, autoridade incontestável, modelo de virtudes e emanação do poder paternal na escola (Bond 1991).

O ambiente na sala de aula chinesa é austero, formal e fortemente hierarquizado, e o aluno, como forma de apreço e respeito pelo ensinante, evita fazer perguntas pois elas poderiam implicar que o professor não tivesse explicado bem a matéria, levando-o perder a face. A aula é sempre orientada pelo docente, que controla os diferentes momentos e é visto também, na opinião de Paine (1990), como um artista cujo desempenho deve ser apreciado e respeitado pelos aprendentes. Na cultura de ensino-aprendizagem chinesa, o professor é percecionado como autoridade 
e depositário do saber, dele se esperando a exposição (e a ostentação) de conhecimentos e uma atitude séria, incompatível com o recurso a jogos ou dramatizações, o que, segundo Hui (1997), inviabiliza a implementação do ensino comunicativo de línguas na China.

Neste contexto, o docente ocupa o papel central das atividades desenvolvidas nas salas de aulas chinesas, mantendo-se distanciado dos seus alunos e colocando-se em cima do estrado. Esse foi o resultado das observações de aulas realizadas por Paine (1990) durante dois anos em escolas chinesas dos ensinos primário e secundário.

A cultura de ensino-aprendizagem chinesa também valoriza enormemente a memória como meio de aquisição e retenção de conhecimentos (Hu 2002), seguindo a tradição secular da aprendizagem de cor dos milhares de carateres e de trechos de textos clássicos da literatura chinesa, considerados paradigmáticos para a análise minuciosa da morfossintaxe. O conhecimento e a utilização correta das normas gramaticais são vistos como muito úteis para os aprendentes pois dão-lhes segurança para os exames que, tradicionalmente, valorizam esses conhecimentos. Por norma, os aprendentes chineses elaboram listas extensas de vocabulário para memorizarem, na convicção de que, a par do conhecimento das regras de gramática, elas lhes permitirão conhecer muito bem a língua-alvo. Essa estratégia de memorização de conteúdos é encorajada pelos docentes, acreditando que aprender de cor palavras e frases (ainda que sem entender o significado das mesmas) acabará por levar os estudantes a utilizá-las de forma correcta. O recurso à denominada "leitura intensiva" de textos é igualmente uma estratégia metodológica muito utilizada pelos professores chineses de línguas estrangeiras; é feita palavra a palavra, ou frase a frase, de modo a que o aprendente desenvolva o hábito de ler os textos devagar, traduzindo vocábulo a vocábulo para chinês, e implicando que muitos estudantes não sejam capazes de compreender o que estão a ler sem tradução (Dzau 1990).

Outra caraterística importante da cultura chinesa de ensino-aprendizagem é o papel central atribuído à língua materna na aprendizagem de uma LE, o que implica a compreensão do léxico e explica o hábito da tradução permanente para a L1 (e também a partir dela) de palavras, frases e excertos da língua-alvo. Nesta perspetiva, uma língua é sobretudo explicada, mais do que ensinada, não havendo, em consequência, espaço para a interação verbal na LE.

A mudança de paradigma de ensino-aprendizagem na China, apesar das tentativas governamentais de introdução do ensino comunicativo de línguas nos anos 90 do século XX, tem deparado com a resistência dos professores (Jin e Cortazzi 2006). Para o facto são apontados vários fatores, um dos quais, e talvez o mais significativo, é a própria cultura tradicional de ensino, nomeadamente as convicções subjacentes à natureza e às estratégias do ensino e da aprendizagem e aos papéis dos professores e dos aprendentes, a que se junta a deficiente formação pedagógica dos docentes e a sua escassa proficiência na língua-alvo - razão, entre outras, por que a interação verbal na aula é evitada.

A resistência à implementação daquelas reformas por parte dos docentes chineses deve-se, segundo Tong (2010), à tensão entre as convicções pessoais e as novas orientações e teve como consequência, segundo ele, o regresso dos professores à segurança sentida pelo familiar método tradicional da gramática-tradução, percecionado por eles como o mais correto.

As razões apontadas por Hui (1997) para explicar esta "cultura de relutante conformidade" (Tong 2010: 236) são diversas: 
i. a pouca motivação dos professores para investirem mais na reflexão sobre práticas pedagógicas, nas necessidades de aprendizagem e na elaboração de materiais, dado que são mal remunerados;

ii. a avaliação do desempenho docente, focada exclusivamente nas competências didáticas na LE, no controlo sobre a turma, na utilização do quadro, ignorando o processo de aprendizagem;

iii. a matriz cultural confucionista chinesa, que implica a procura contínua de compromissos entre as pessoas e o respeito pela hierarquia social, e que, no contexto de ensino-aprendizagem, se manifesta pela relutância dos aprendentes em intervir na sala de aulas (daí que a produção escrita individual, da qual está tradicionalmente ausente a manifestação de sentimentos ou de opiniões pessoais, seja escolhida em detrimento da conversa a pares, por exemplo);

iv. a sobrelotação das salas de aulas, acolhendo tipicamente 40,60 ou até 80 alunos com diferentes níveis de proficiência linguística, ditando que, por norma, os docentes optem por adequar o ritmo e a progressão do ensino ao desempenho dos melhores estudantes;

v. o facto de a maioria dos professores chineses, qualquer que seja o nível de ensino, ser incapaz de compreender inteiramente os métodos comunicativos e de distinguir situações e atividades de comunicação autênticas de outras, a par de uma grande falta de conhecimentos de pragmática da língua estrangeira que ensina (nomeadamente através do uso de uma linguagem descontextualizada e desadequada da situação de comunicação).

O apego à tradição cultural milenar emerge também da retórica oficial, através da exaltação recorrente e da adaptação da tradição confuciana à sociedade contemporânea (Yu 2008; Wong 2015), razão por que se pode considerar, a par das tentativas de reforma do sistema educativo, nomeadamente no respeitante à adoção de novas metodologias no ensino de línguas estrangeiras, e de modo algo paradoxal, um movimento de retorno aos valores culturais tradicionais.

Normalmente, e decorrente das caraterísticas peculiares da cultura chinesa, o aprendente chinês é visto como profundamente moldado pelo seu arquétipo cultural de ensino-aprendizagem e, portanto, como obediente à autoridade, passivo, sem capacidade de raciocínio crítico, recorrendo a estratégias de aprendizagem assentes sobretudo na memorização maquinal (e, portanto, numa aprendizagem superficial), e nada disposto a participar nas aulas. Além disso, é percecionado por professores ocidentais como resistente a formas de ensino diferentes das tradicionais (Kember 2000).

Os aprendentes chineses a estudar em ambientes de ensino diferentes dos que lhes são familiares passam supostamente por um processo complexo de adaptação à nova realidade que inclui uma diversidade de fatores, não apenas pedagógicos mas também decorrentes do contacto direto com os valores e a cultura (Tait 2011-2012) do local e da instituição de acolhimento. No novo contexto de aprendizagem, como em universidades que adotaram estilos de ensino ocidentais, os estudantes chineses esperam que os professores correspondam às suas perspetivas, nomeadamente através dos métodos de ensino, da orientação e do acompanhamento da aprendizagem, papel a que eles estão habituados na sua cultura de ensino, mas acabam por constatar, defendem Zhu e Gao (2013), que essas expectativas não se concretizam.

O esforço de adaptação destes alunos a contextos diferentes de ensino-aprendizagem parece também ter vantagens. Devido às novas exigências que lhes são colocadas, eles podem adaptar-se a novos objetivos e a novas estratégias de aprendizagem e, ao mesmo tempo, melhorar a proficiência na LE e tornar-se mais autónomos e responsáveis em relação à própria aprendizagem $(\mathrm{Gu}$ e Schweisfurth 2006). 


\section{Análise dos resultados}

O inquérito por questionário incluía afirmações relacionadas com o método tradicional da gramática-tradução predominante ainda nos dias de hoje em toda a China e a cujas práticas os alunos naturalmente aderem e com as quais previsivelmente mais se identificam. As afirmações procuravam clarificar a perceção e o grau de adesão e de concordância dos aprendentes em relação a questões como a importância da tradução e da língua materna no ensino-aprendizagem de uma língua estrangeira, as estratégias de aprendizagem que mais os cativam (a memorização de listas de vocabulário isolado, por exemplo) e o papel que deve ser assumido pelo professor e pelos alunos.

$\mathrm{Na}$ tentativa de compreender o modo como os alunos encaram a possibilidade de aprender recorrendo a outras metodologias e estratégias, foram também incluídas afirmações relacionadas com a abordagem comunicativa que preconiza práticas dentro da sala de aula profundamente divergentes daquelas que constituem o background cultural e pedagógico dos aprendentes. Com isso pretendia-se avaliar o grau de abertura e de sensibilidade para estas práticas amplamente aceites e já enraizadas no Ocidente mas que têm tido pouca aceitação na cultura de ensino de raiz confucionista, nomeadamente chinesa. Os aprendentes foram incentivados a manifestar-se sobre a natureza das atividades a realizar dentro da sala de aula, sobre a importância das atividades comunicativas como forma de aprender uma nova língua, e sobre outra atitude e outros papéis de alunos e professor dentro da sala, diferentes daqueles a que convencionalmente estão habituados. Foram ainda incluídas afirmações que procuravam clarificar o ponto de vista dos informantes em relação ao material didático e à importância das novas tecnologias no ensino-aprendizagem de uma língua estrangeira.

Neste trabalho são apresentados apenas alguns dos resultados da investigação considerados mais relevantes.

Para perceber as convicções dos alunos em relação às práticas tradicionais de ensino em que foram escolarizados, elaboraram-se afirmações relacionadas com o estudo da gramática, a realização de exercícios estruturais, e a importância e o papel da língua materna e da tradução na aprendizagem da língua-alvo.

As afirmações 1. Aprende-se melhor português se o professor explicar o vocabulário em chinês, 2. Aprende-se melhor português se o professor explicar as regras gramaticais em chinês e 3. Aprende-se melhor português através de listas de vocabulário novo com a tradução para chinês destinavam-se a compreender em que medida, e apesar de todo o desenvolvimento tecnológico a que se tem assistido nas últimas décadas, o acesso à Internet, a utilização de computadores e de outros meios digitais, a língua materna dos aprendentes é um recurso essencial para a aprendizagem. Setenta e dois por cento dos respondentes declararam concordar com a asserção 1. (Figura 1).

A afirmação 2 recebe $81 \%$ de concordância e a 3. apresenta um nível de concordância de $83 \%$ (Figura 2).

Os resultados obtidos com as três afirmações são expressivos em relação ao nível de concordância.

Estes estudantes consideram necessária a explicação do léxico e das normas gramaticais na sua língua materna. Conhecer o vocabulário e as regras gramaticais com recurso à L1 é inequivocamente muito importante, pelo que se pode concluir que, eventualmente, também se sentem mais 


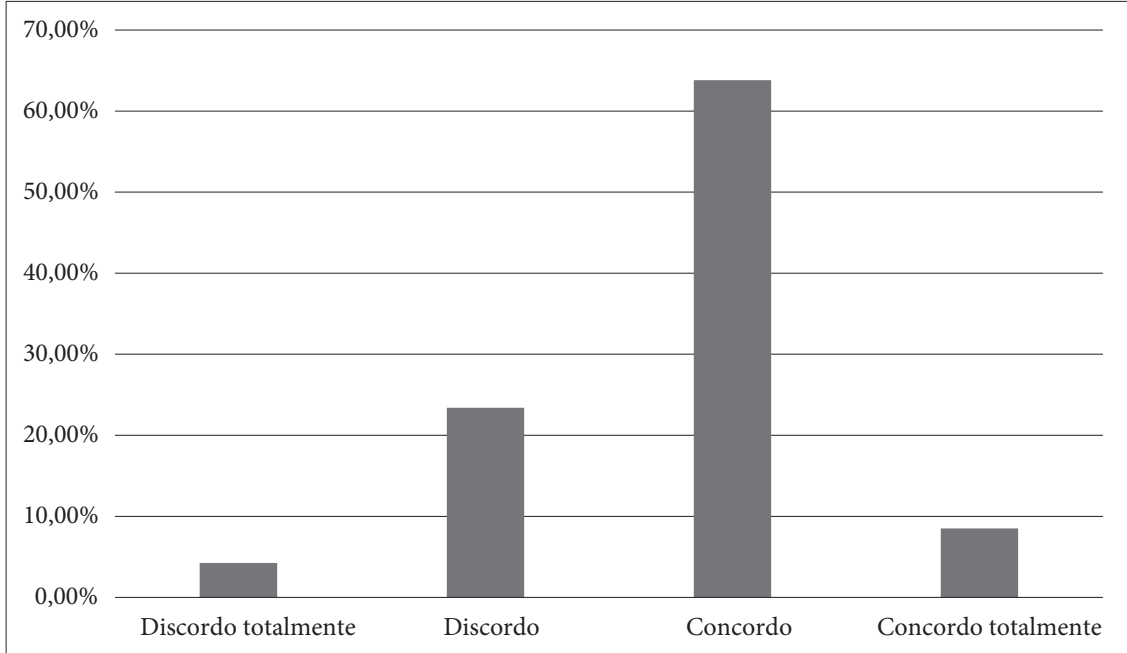

Figura 1. Aprende-se melhor português se o professor explicar o vocabulário em chinês

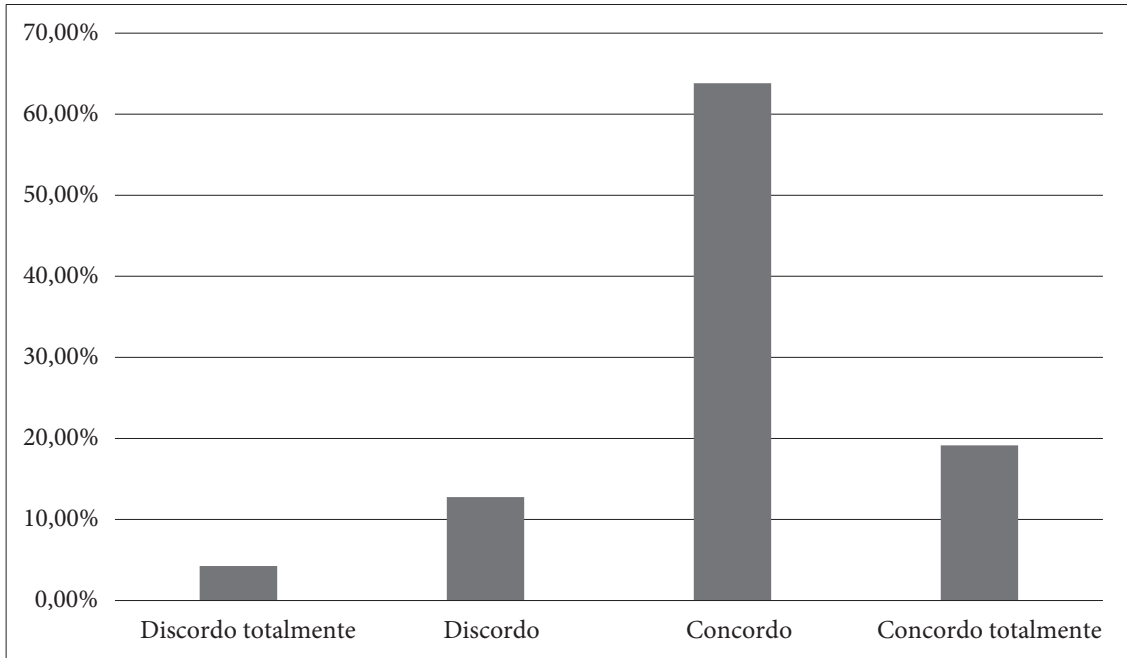

Figura 2. Aprende-se melhor português através de listas de vocabulário novo com a tradução para chinês 


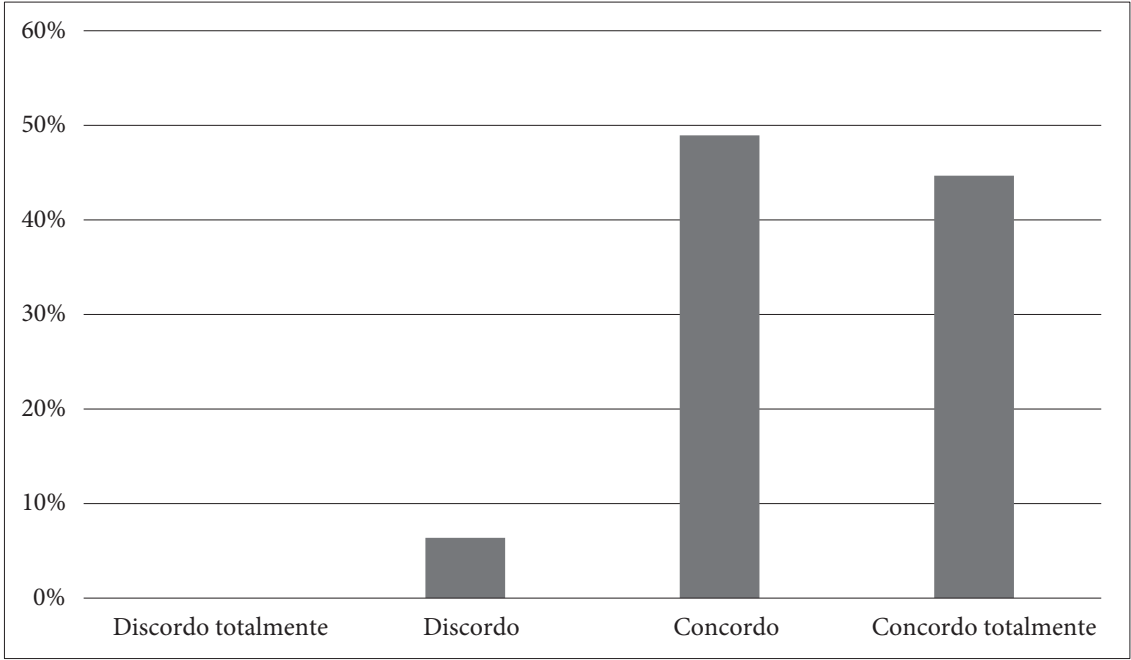

Figura 3. Nas aulas de português com professores ocidentais, os alunos devem participar em atividades comunicativas (por exemplo, conversa a pares)

seguros com um professor chinês para lhes ensinar a língua estrangeira. Este facto não surpreende, uma vez que o ensino de uma LE (inglês, no caso da RPC), que eles iniciam nos primeiros anos da escolaridade, é ministrado por um professor chinês com recurso quase exclusivo à língua materna.

Com as afirmações 23. Nas aulas de português com professores chineses, os alunos devem estudar principalmente a gramática da língua e 24. Nas aulas de português com professores ocidentais, os alunos devem participar em atividades comunicativas - por exemplo, conversa a pares (Figura 3) pretendia-se avaliar as opiniões dos respondentes sobre os professores.

No formato da licenciatura em Estudos Portugueses da UMAC, no $1 .^{\circ}$ ano, os docentes chineses ou bilingues de PLE têm a seu cargo, por norma, as disciplinas que se concentram no ensino -aprendizagem da gramática e da componente escrita, e os professores portugueses são responsáveis pelas cadeiras das componentes da compreensão e produção oral e da cultura. Os dados obtidos com a asserção 23 revelam que $60 \%$ dos aprendentes concordam com a afirmação, o que parece contradizer a necessidade do recurso à L1 como forma de ajudar a compreender a gramática e o vocabulário da língua-alvo manifestada nas afirmações 1, 2 e 3. Este entendimento é reforçado pelas respostas à afirmação 24 , em relação à qual $94 \%$ dos aprendentes manifestam concordância (Figura 3).

Estes resultados apontam para um perfil de aprendente ainda aconchegado à sua língua materna como veículo de aprendizagem do novo idioma que, preferencialmente, deve ser ensinado por um professor que partilhe a mesma língua e identidade cultural. No entanto, há uma forte evidência de abertura às práticas comunicativas na sala de aula e o reconhecimento das vantagens em aprender a língua-alvo com docentes nativos. 
Sendo a gramática da língua o foco do método tradicional da gramática-tradução, a realização de exercícios estruturais que permitem aos alunos mecanizar procedimentos e melhor captar a dinâmica do funcionamento do idioma são bem aceites por parte dos aprendentes. Relativamente à afirmação 6. Aprende-se melhor a gramática da língua portuguesa a fazer repetidamente muitos exercícios de gramática, $74 \%$ dos respondentes afirmam concordar com esta prática. A realização de muitos exercícios estruturais é, na perspetiva da cultura de aprendizagem chinesa, tarefa obrigatória que se impõe (entre outras atividades) e que define um aluno dedicado e responsável.

Na pergunta de resposta aberta sobre o que é um bom aluno de língua estrangeira (Figura 4), os respondentes revelaram, como caraterística mais importante, o esforço, a dedicação, o estudo árduo.

Esta opinião de topo está indelevelmente associada à tradição educativa chinesa que exalta o esforço e a determinação pessoal para a aprendizagem como o mais nobre objetivo de vida (Li 2004; Mak 2008) e que, em termos práticos, considera um bom aluno aquele que estuda arduamente no sentido da memorização de conteúdos (Marton, Wen e Wong 2005), da preparação para os exames (Huang e Leung 2004), da realização dos trabalhos de casa, da elaboração de listas de vocabulário e da atenção prestada ao professor nas aulas (Wang e Chen 2013). Este perfil está também profundamente em harmonia com os princípios confucianos que preconizavam a importância do trabalho árduo para a afirmação e valorização do ser humano. Confúcio interpelava: "é possível amar alguém sem o fazer trabalhar muito? É possível fazeres o melhor que podes por alguém sem o educar?" (Confúcio s.d.: 88).

As asserções 4. Aprende-se melhor português a decorar listas de vocabulário novo e 5. Aprende-se melhor português a decorar os textos procuravam avaliar as conviç̧ões e perceções dos respondentes em relação às práticas letivas mais comuns ao longo do seu percurso escolar. Pretendia-se perceber a importância que ainda atribuem à memorização de vocabulário e de textos como forma de aprender uma língua estrangeira, hábito que adquirem desde cedo porque é muito importante para o conhecimento dos milhares de caracteres da língua materna que precisam de saber, processo difícil (Becker 2006) que Bond (1991: 27) realça: "the demands on one's memory capacity for receiving and producing the written Chinese are enormous". A memorização através da reprodução exata do que o professor ensina (repetição e cópia) é considerada, no âmbito da pedagogia chinesa, como uma estratégia basilar para alcançar um bom desempenho académico (Cooper 2004).

Em relação à afirmação 5. Aprende-se melhor português a decorar os textos, o nível de concordância é de $49 \%$, e $51 \%$ dos participantes manifestam discordância. Estes últimos dados parecem indiciar que a memorização de textos integrais é percecionada como tarefa difícil e que os aprendentes já não encaram como crucial na aprendizagem da nova língua. Esta perceção é confirmada de modo mais concludente com as respostas à afirmação 10. do questionário - Memorizar é a melhor forma de aprender uma língua - com 79\% dos respondentes a discordarem (Figura 5).

Relativamente ao vocabulário, que nos manuais chineses é apresentado em longas listas, com a tradução para chinês, a opinião dos aprendentes parece ser inequívoca. Noventa e oito por cento assumem ser muito importante decorar listas de vocabulário, com uma percentagem de $40.2 \%$ declarando concordar completamente (Figura 2). Hu (2002) descreve a cultura de ensino-aprendizagem na China como muito tradicional, apontando como uma das suas caraterísticas o facto de as matérias serem ensinadas de modo cuidadoso e sequenciado, de maneira a que os estudantes as possam memorizar, repetir e compreender. 


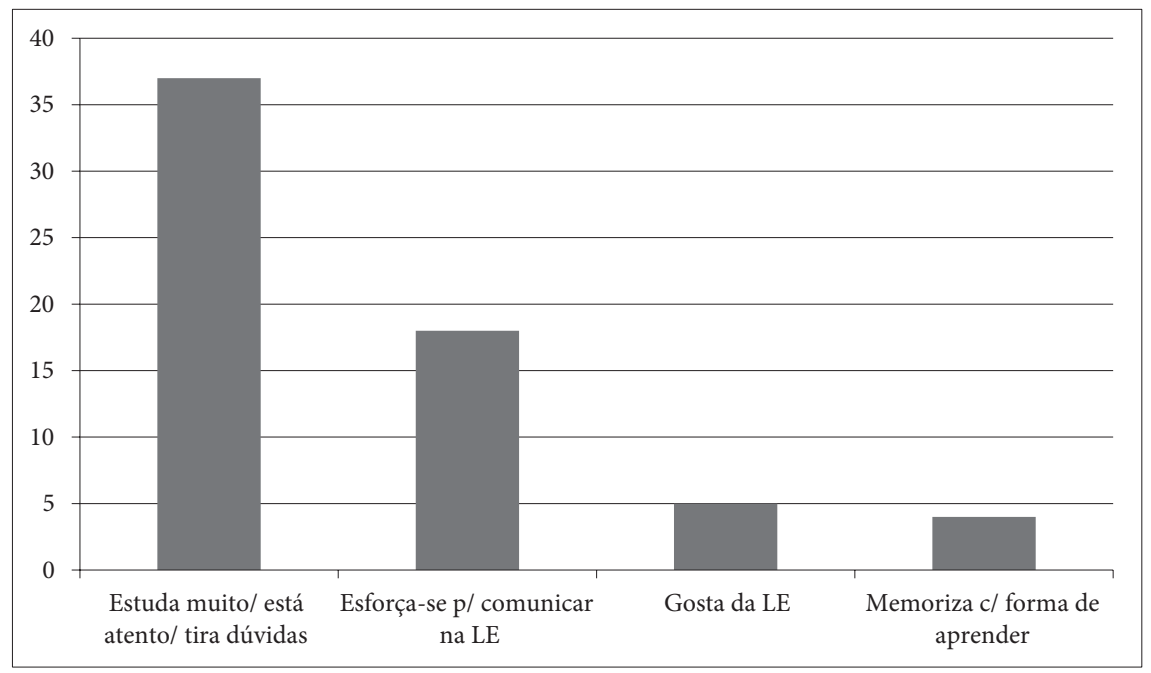

Figura 4. Um bom aluno de língua estrangeira

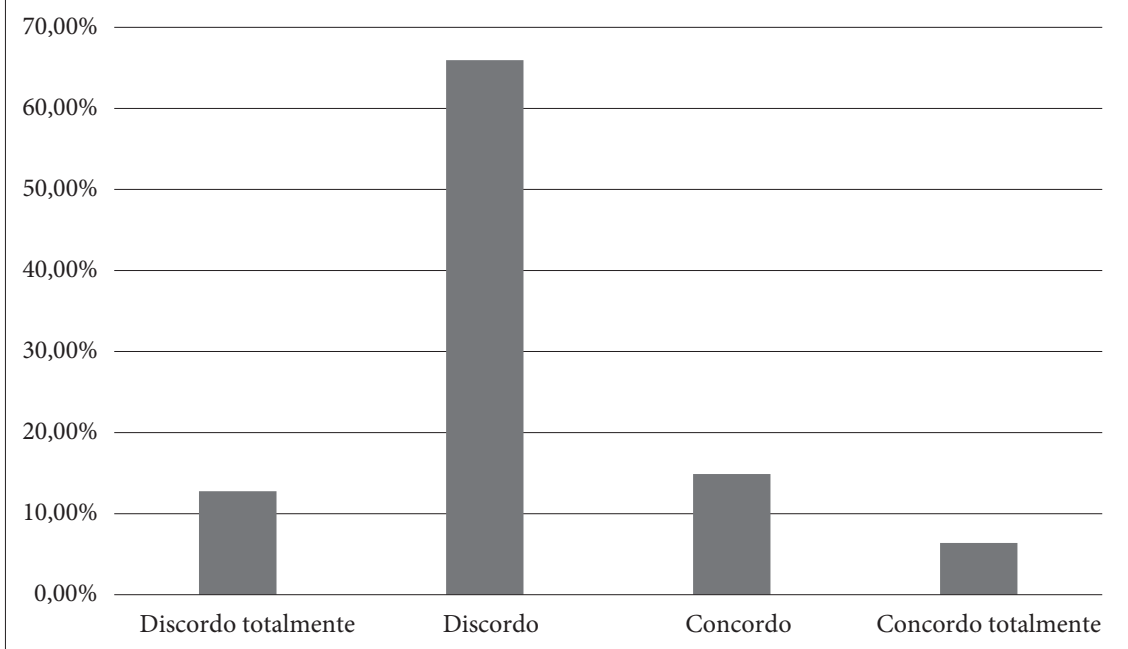

Figura 5. Memorizar é a melhor forma de aprender uma língua 
Estes resultados devem ser tidos em conta por um professor ocidental quando tem pela frente um grupo de aprendentes chineses, para os quais a arrumação do vocabulário significa organização e suporte para o estudo diário ou para os momentos de avaliação. Por isso, todo o léxico (contextualizado) decorrente do estudo de um novo texto deve ser apresentado a estes estudantes de forma arrumada. As notas soltas que um docente ocidental frequentemente escreve no quadro tendem a ser desvalorizadas pelos aprendentes chineses, como temos constatado pela nossa própria experiência de ensino de PLE a estes estudantes.

Os resultados obtidos apontam para um perfil de aprendente profundamente convicto da importância das práticas de ensino inerentes à cultura chinesa de ensino-aprendizagem. No entanto, com base nas opiniões relativamente a outras afirmações do questionário, parece poder perspetivar-se um perfil de aluno em processo de mudança: em alguns aspetos, por um lado, revela forte convicção sobre a importância das práticas tradicionais de ensino; por outro, parece já mais liberto e mais recetivo a novas metodologias e ao ensino ministrado por professores não chineses. Por exemplo, quanto à afirmação 8. O mais importante na aprendizagem de português é saber as regras da gramática, $45 \%$ dos respondentes, surpreendentemente, afirmam discordar, e apenas 55\% concordam. O mesmo cenário de opinião é revelado pela afirmação 9. É impossível comunicar em português sem conhecer as regras da gramática, com a qual 60\% dos respondentes discordam e 55\% manifestam concordância. Não desvalorizando a importância da gramática na aprendizagem da LE, esta já não constitui, na opinião destes estudantes, o foco da aprendizagem.

Quanto aos resultados decorrentes da afirmação 26. Um bom professor de português deve corrigir sempre os erros dos alunos, $96 \%$ dos aprendentes afirmam concordar. Na pergunta de resposta aberta sobre o que consideram ser um bom professor de língua estrangeira (Figura 6), os respondentes destacam também, como terceira caraterística mais importante, aquele que corrige os erros. Como atributo mais relevante sobre o mesmo tópico assinalam a capacidade para proporcionar bom ambiente nas aulas, e valorizam, logo a seguir, a disponibilidade do docente para a interação na língua-alvo.

Nesta perspetiva, o conhecimento da língua deve ser minucioso, detalhado, exaustivo, e só a longo prazo, chegado a esse patamar de domínio da língua-alvo, o aprendente poderá ser um utilizador proficiente. Isto explica em parte a completa desvalorização das atividades comunicativas na aprendizagem da língua, na perspetiva do método da gramática-tradução. Lee (2007) concluiu que os alunos de matriz cultural confuciana, estudando num contexto de ensino diferente do habitual, revelavam receio de errar. Por isso, na sala de aula, evitavam revelar aquilo que viam como fraquezas (como cometer erros, por exemplo), expondo-se a uma avaliação negativa que os levaria a perder a face. A correção dos erros é muito valorizada pelos respondentes e remete para uma ideia de perfeição completamente congruente com a cultura confuciana. Habitualmente, a característica mais marcante atribuída aos aprendentes de herança cultural confucionista é a convicção de que o sucesso se deve ao esforço (Volet 1999), pelo que um bom estudante deve ser muito trabalhador e perseverante (Shi 2006).

Na herança pedagógica de matriz cultural confuciana é atribuída grande importância aos textos escritos, nomeadamente aos manuais escolares, elaborados com base em orientações e programas prescritos pelos decisores da política educativa. Trata-se, portanto, de uma realidade de ensino-aprendizagem em que abundam materiais escritos que fornecem aos professores, sobretudo aos mais jovens e, portanto, menos experientes, sugestões de ensino e conteúdos a abordar (Fang 


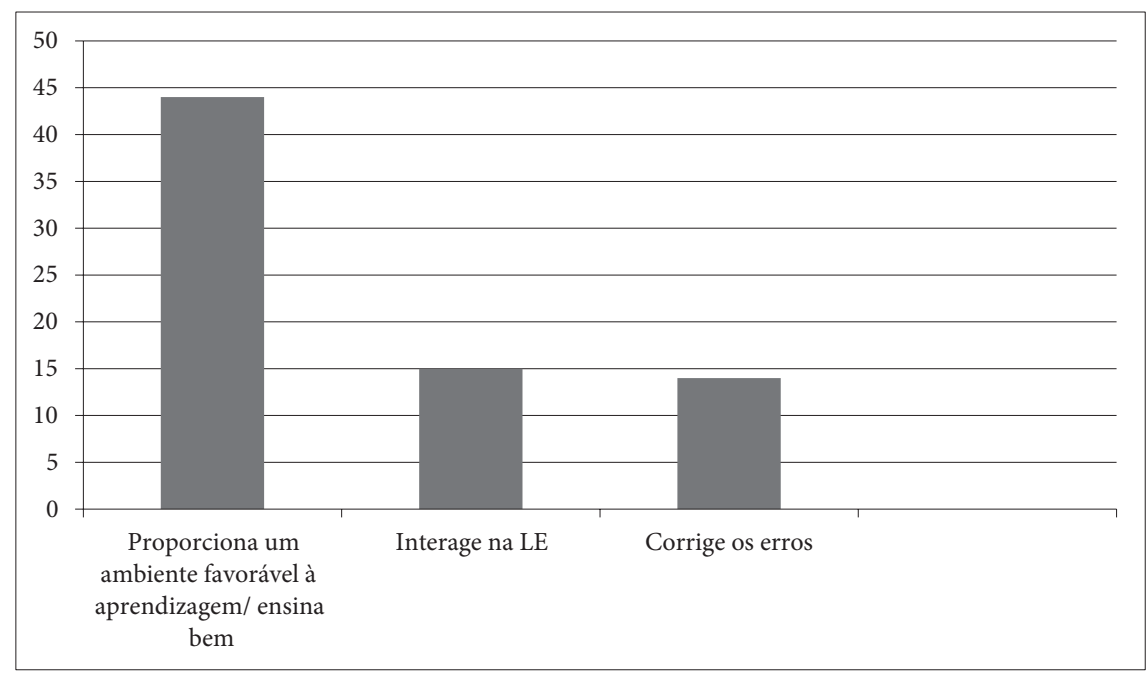

Figura 6. Um bom professor de língua estrangeira

e Gopinathan 2009). Em semelhante contexto pedagógico de supremacia do texto, os materiais em questão, juntamente com o professor, acabam por tornar-se na única fonte de conhecimento (Fang e Gopinathan 2009).

Olhando para os resultados obtidos com a afirmação 13. Os textos escritos são mais importantes do que os textos orais, constata-se que $89 \%$ dos alunos discordam. Estes dados confirmam um perfil de aprendente que gradualmente se vai distanciando de modelos rígidos da sua cultura de aprendizagem e que parece aceitar com naturalidade novos paradigmas educativos.

Outros dados obtidos a partir deste questionário revelam-se também muito significativos e devem ser considerados no momento de trabalhar com este público aprendente. Estes alunos reconhecem a importância das atividades comunicativas e do uso da língua como forma de a aprender. Em relação à afirmação 18. O professor deve dar tempo da aula a atividades que incentivam os alunos a comunicar em português, $94 \%$ dos respondentes concordam. A afirmação 19. Usar a língua portuguesa a comunicar é a melhor forma de a aprender recebe $96 \%$ de opiniões concordantes. Ambas as afirmações revelam o entendimento de que uma língua não se aprende apenas pelo conhecimento da sua gramática e do léxico, e o seu uso é uma etapa necessária no percurso da aprendizagem. Liu e Littlewood (1997) concluíram, com base num estudo com alunos de Hong Kong de inglês língua estrangeira (ILE), que estes revelaram gostar de interagir verbalmente nas aulas e que a inicial relutância dos aprendentes em participar em atividades comunicativas tinha como causa o percurso anterior de aprendizagem, marcado pela experiência contínua de ouvir o professor em silêncio. A atitude tradicional dos alunos chineses em relação aos docentes é de respeito, obediência, confiança e, normalmente, de dependência, não participando ativamente no processo de aprendizagem nem nele tendo responsabilidade direta. No contexto da cultura de ensino-aprendizagem de raíz confuciana, a "participação ativa” destes estudantes, explicam Wang e Chen $(2013,132)$, é como uma "quiet attentiveness". Daí decorre que o envolvimento 
do aprendente chinês com os conteúdos veiculados pelo discurso do docente não seja verbal e a aprendizagem se faça ouvindo, não comunicando nem com o ensinante nem com outros estudantes. Questionar o docente ou manifestar pontos de vista pessoais não se coaduna com o comportamento dos estudantes chineses, treinados como são, desde o início da escolaridade, a permanecerem calados nas aulas e a aprenderem a matéria, memorizando-a. No entanto, a importância que os participantes neste estudo dão à interação verbal na sala de aula parece apontar para a aceitação de novos papéis de alunos e professores, dado que 68\% declaram discordar da afirmação 21. O professor não deve ser interrompido durante a aula (Figura 7).

Tradicionalmente, associa-se estes aprendentes a uma imagem de passividade, à ideia de que não interagem com o docente ou só o fazem quando solicitados. Se isso é de facto visível na prática letiva quotidiana com estes alunos, aos olhos de um professor ocidental impõe-se antes de qualquer julgamento superficial e não documentado refletir e aprofundar o conhecimento do background cultural que dita a postura destes estudantes na sala de aula. À luz da matriz cultural confuciana, do aluno chinês espera-se a reprodução daquilo que o professor considera importante, a passividade e o silêncio, na convicção de que um jovem deve ser "obediente no exterior [do lar], parco em palavras mas digno de confiança no que diz" (Confúcio s.d.: 12).

Embora aparentemente pareçam passivos dentro da sala de aula, mais disponíveis para ouvir o professor do que para interagir, estes aprendentes apenas precisam de um ambiente favorável e de oportunidades para se expressarem na língua-alvo. Na pergunta de resposta aberta sobre o que consideram ser um bom professor de língua estrangeira (Figura 6), a perceção que é a primeira escolha dos respondentes - e que tem igualmente uma significativa frequência de opiniões partilhadas nas respostas à pergunta Quais são as condições ideais para aprender uma língua estrangeira? (Figura 8) -, e aparece bem distanciada de outras caraterísticas que atribuem ao bom docente, é a de que ele deve proporcionar um ambiente favorável à aprendizagem e ensinar bem, dados que parecem indicar uma grande expectativa em relação ao estabelecimento de uma atmosfera familiar, tão prezada nas sociedades de arquétipo cultural confuciano, possivelmente como forma de suavizar a integração num novo contexto de ensino-aprendizagem, diferente daquele que estes aprendentes vivenciaram ao longo do percurso escolar anterior - é também traço da cultura de ensino-aprendizagem chinesa que estabelece um contrato tácito entre ensinante e aluno baseado no apreço recíproco: o aprendente é respeitador e esforçado, cabendo ao docente garantir o sucesso do estudante nos exames (Yu 2008).

A afirmação 30, Numa aula de língua estrangeira o aluno deve aprender a comunicar as suas opiniões e ideias confirma esta perceção, uma vez que os respondentes, por unanimidade, declararam concordar.

As opiniões manifestadas através das resposta abertas à terceira pergunta, incidindo sobre as condições que os respondentes acham ideais para aprender uma língua estrangeira (Figura 8), corroboram também, de modo perentório, a perspetiva de que, para eles, é muito importante comunicar para desenvolverem a competência comunicativa na LE, o que, de novo, parece contrariar em absoluto a ideia do aprendente chinês passivo, silencioso, mero recetáculo e reprodutor de conhecimentos, inteiramente avesso à interação na aula. Estes resultados, por outro lado, apontam para a constatação de que, num contexto de aprendizagem em que têm condições e são incentivados, os alunos chineses apreciam e mostram-se capazes de interagir na língua-alvo, envolvendo-se ativamente na aprendizagem. Essa é também a constatação de Kember (2000: 99) quando consi- 


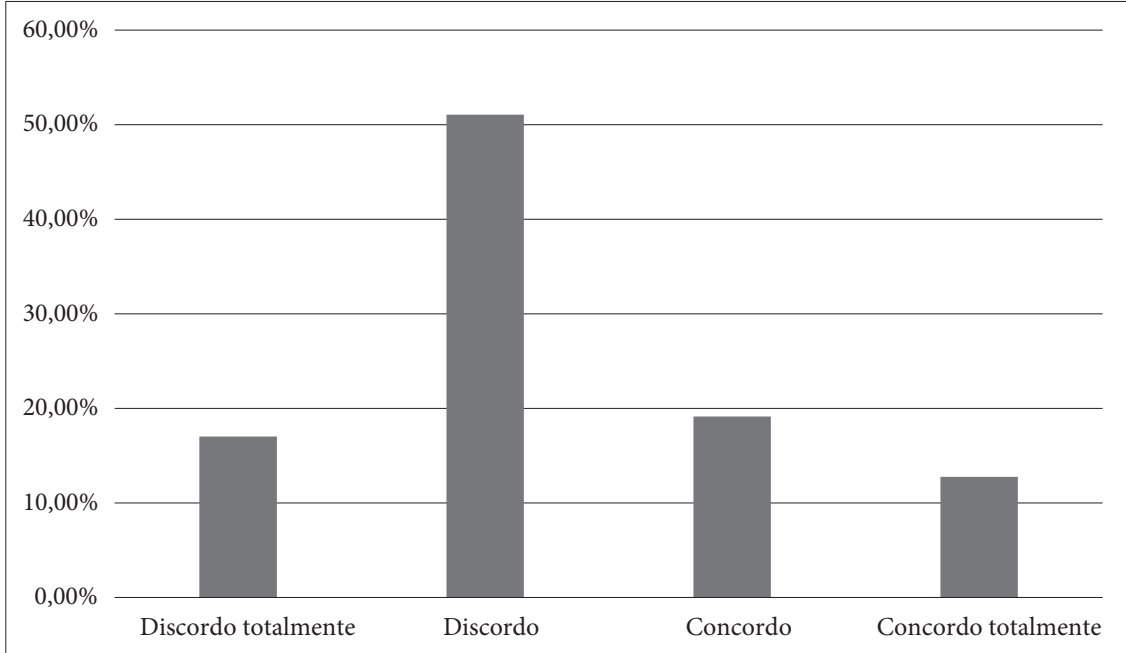

Figura 7. O professor não deve ser interrompido durante a aula

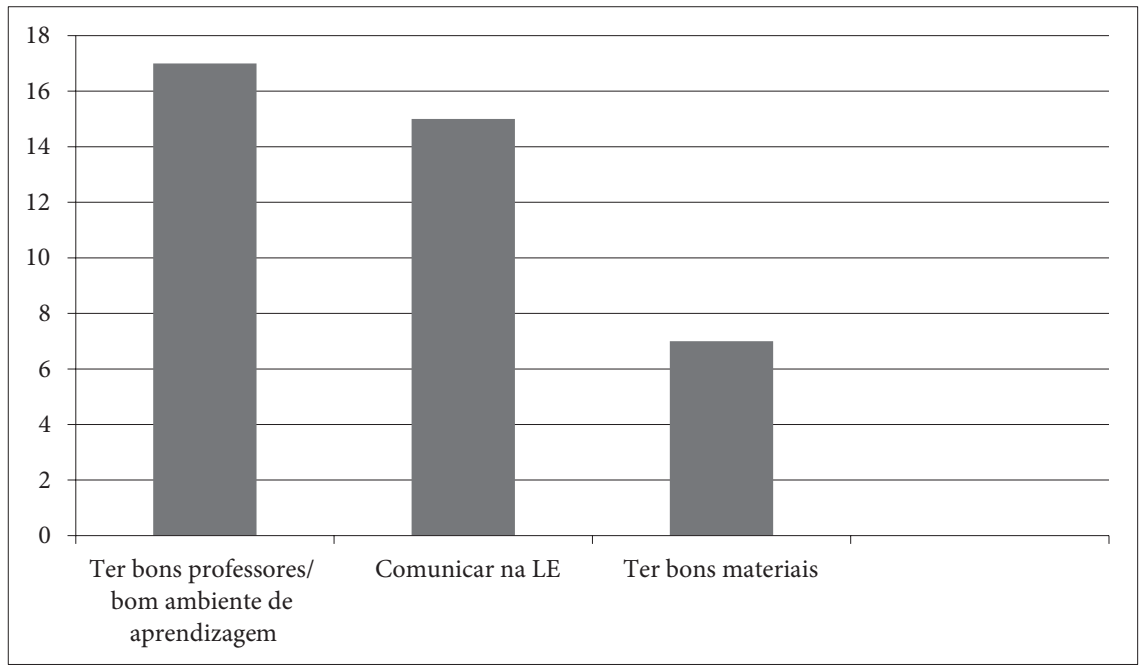

Figura 8. Condições ideais para aprender uma língua estrangeira 
dera que os aprendentes chineses são capazes de se ajustar a "formas ativas" de aprendizagem se lhes for dada a oportunidade, e a conclusão de Nunan (1991) num estudo com alunos de ILE do Sudoeste asiático, que consideraram a interação em inglês em contexto de aprendizagem formal como a mais vantajosa estratégia para melhorar a proficiência comunicativa na língua-alvo.

Outra consequência muito relevante dos resultados do nosso trabalho, em linha com a evidência empírica de outras investigações (e.g. Liu e Littlewood 1997; Gu e Schweisfurth 2006), é que eles legitimam o entendimento de que uma causa muito significativa para a relutância dos alunos chineses em interagir na aula é o facto de estarem acostumados a um estilo de ensino centrado no professor, muito formal, que lhes exige silêncio e recato, não lhes permitindo falar.

Littlewood (2000), num estudo com aprendentes chineses, tentou procurar uma resposta para a pergunta "será que os estudantes asiáticos querem realmente ouvir e obedecer?" Sem negar a herança e a influência dos fatores culturais, este autor coloca a tónica no contexto de aprendizagem como condicionador das atitudes e comportamentos dos aprendentes, defendendo que as perspetivas habituais sobre os estudantes asiáticos e a sua cultura de aprendizagem - em particular a conviç̧ão de que eles vêem o professor como autoridade e fonte de conhecimentos - são preconceituosas e por isso se torna necessário compreender de maneira mais profunda a natureza e a extensão das influências culturais na aprendizagem. Gu e Schweisfurth (2006) chegaram a uma conclusão idêntica, tendo constatado que os aprendentes ILE em diversas universidades da China, quando confrontados com uma cultura de ensino-aprendizagem ocidental, se envolviam num processo de adaptação e de mudança influenciado por fatores contextuais, psicológicos, sociais e inter-pessoais. Os resultados do nosso trabalho de investigação parecem confirmar essa realidade.

Os respondentes revelam-se também como jovens modernos, utilizadores incondicionais das novas tecnologias, mostrando entender os benefícios destes novos recursos de aprendizagem, conforme a concordância de $96 \%$ com a afirmação 34, As novas tecnologias e os recursos multimédia ajudam muito a aprender português, permite concluir.

\section{Conclusões}

Num ambiente multicultural, e perante o desafio de ensinar aprendentes de matriz cultural confuciana, é de particular importância, antes de tudo, o conhecimento do seu background cultural.

Num contexto de aumento tão significativo de estudantes chineses a estudar atualmente a língua portuguesa com o objetivo de a usar num futuro próximo como instrumento de trabalho, impõe-se aos docentes nativos de língua portuguesa conhecer inequivocamente, e de forma distanciada de estereótipos, a realidade cultural e o percurso escolar destes alunos, bem como as suas expectativas e perceções sobre o ensino-aprendizagem de uma língua estrangeira. Constatando a relevância determinante do arquétipo de ensino chinês na aprendizagem de línguas estrangeiras, e para evitar um ambiente de antagonismo nas salas de aulas multiculturais (Rao 2006), é importante que os professores de línguas estrangeiras sejam sensatos na escolha de métodos, de forma a harmonizarem a cultura tradicional chinesa com outras práticas pedagógicas como, por exemplo, as que a abordagem comunicativa preconiza.

Chegados ao ensino superior, e no momento de aprender um novo idioma (PLE, no caso), o formato tradicional de ensino-aprendizagem predominante por toda a China é aquele com que, 
previsivelmente, os aprendentes mais se identificam. Espera-se que estes alunos manifestem uma forte convicção em relação a algumas das práticas preconizadas pelo método da gramática-tradução - lugar dado à língua materna, à memorização, à centralidade da gramática.

Os resultados do presente estudo confirmam que estes pressupostos apenas se verificam parcialmente. Por um lado, os respondentes mostram manter-se fortemente arreigados ao seu arquétipo cultural de ensino-aprendizagem, nomeadamente a estratégias de aprendizagem, a métodos de ensino e a convicções identitárias; por outro lado, quer seja pela capacidade de adaptação aos novos tempos e a novos contextos de aprendizagem, quer pelo sentido prático, ou simplesmente por um modo de pensar diferente das gerações anteriores, mostram-se mais flexíveis em relação a novas metodologias, mais libertos do paradigma de ensino tradicional em que foram escolarizados, capazes de aceitar e de assumir novos papéis dentro da sala de aula (diferentes daqueles que, tradicionalmente, são atribuídos ao docente e aos estudantes), e de reconhecer a importância dos modernos recursos tecnológicos para a aprendizagem de uma língua estrangeira.

Em contraste com a imagem do aprendente chinês relutante em envolver-se em interações verbais, os resultados da nossa investigação revelam um perfil do estudante de matriz cultural confuciana com caraterísticas bem diferentes: apreciando e considerando importante a interação nas aulas de língua estrangeira e considerando o uso do idioma de aprendizagem como essencial para o desenvolvimento da competência comunicativa.

\section{Referências bibliográficas}

Becker, J. (2006). Dragon rising. Washington, D.C.: National Geographic.

Belchior, M. J. (2011). Chineses aprendem mais português. Revista Macau 23, IV (junho), 49-59.

Biggs, J. B. (1996). Western misperceptions of the Confucian-heritage learning culture. In The Chinese learner: Cultural, psychological and contextual influences (pp. 45-68). Hong Kong: The University of Hong Kong.

Bond, M. H. (1991). Beyond the Chinese face: Insights from psychology. Hong Kong: Oxford University Press. Celce-Murcia, M. (2014). An overview of language-teaching methods and approaches. In Teaching English as a second or foreign language (2-14). Boston: National Geographic Learning-Heinle Cengage Learning.

Chan, C. (2008). Pedagogical transformation and knowledge building for the Chinese learner. Evaluation and Research in Education, 21, 3, 235-251.

Confúcio. s.d. Analectos. Mem Martins: Publicações Europa-América.

Cooper, B. J. (2004). “The enigma of the Chinese learner”. Accounting Education, 13, 3, 289-310.

Dzau, Y. F. (1990). English in China. Hong Kong: API Press.

Fang, Y.; Gopinathan, S. (2009). Teachers and teaching in Eastern and Western schools: A critical review of cross-cultural comparative studies. In International handbook of research on teachers and teaching (pp. 557-572). New York: Springer.

Gu, Q.; Schweisfurth, M. (2006). Who adapts? Beyond cultural models of "the" Chinese learner. Language, Culture and Curriculum, 19, 1, 74-89.

Hu, G. (2002). Potential cultural resistance to pedagogical imports: The case of communicative language teaching in China. Language, Culture and Curriculum, 15, 2, 93-105. 
Huang, R.; Leung, K. S. (2004). Cracking the paradox of Chinese learners: Looking into the mathematics classrooms in Hong Kong and Shanghai. In How Chinese learn mathematics - Perspectives from the insiders (pp. 348-381). Singapore: World Scientific Publishing.

Hui, L. (1997). New bottles, old wine: Communicative language teaching in China. Forum, 35, 4, 38-47.

Jin, L.; Cortazzi, M. (2006). Changing practices in Chinese cultures of learning. Language, Culture and Curriculum, 19, 1, 5-20.

Kember, D. (2000). Misconceptions about the learning approaches, motivation and study practices of Asian studies. Higher Education, 40, 99-121.

Lee, E. L. (2007). Linguistic and cultural factors in East Asian students' oral participation in U.S. university classrooms. International Education, 36, 2, 27-47.

Li, J. (2001). Chinese conceptualization of learning. Ethos, 29, 2, 111-137.

. (2004). A Chinese cultural model of learning. In How Chinese learn mathematics (pp. 124-156). Singapore: World Scientific.

Littlewood, W. (2000). Do Asian students really want to listen and obey? ELT Journal, 54, 1, 31-36.

Liu, N-F.; Littlewood, W. (1997). Why do many students appear reluctant to participate in classroom learning discourse? System, 25, 3, 371-384.

Mak, G. C. L. (2008). Diversity in the Chinese classroom in changing contexts. Evaluation and Research in Education, 211, 3, 252-266.

Marton, F.; Wen, Q.; Wong, K. C. (2005). Read a hundred times and the meaning will appear... Changes in Chinese university students' views of the temporal structure of learning. Higher Education, 49, 291-318.

Nunan, D. (1991). Language teaching methodology: A textbook for teacher. Upper Saddle River, NJ: Prentice Hall.

Oxford, R L. (2003). Language learning styles and strategies: Concepts and relationships. International Review of Applied Linguistics in Language Teaching, 41, 271-278.

Paine, L. W. (1990). The teacher as a virtuoso: A Chinese model for teaching. Teachers College Record, 92, 1, $49-81$.

Rao, Z. (2006). Understanding Chinese students' use of language learning strategies from cultural and educational perspectives. Journal of Multilingual and Multicultural Development, 27, 6, 491-508.

Richards, J. C.; Rodgers, T. S. (2001). Approaches and methods in language teaching. Cambridge: Cambridge University Press.

Shi, L. (2006). The successors to Confucianism or a new generation? A questionnaire study on Chinese students' culture of learning English. Language, Culture and Curriculum, 19, 1, 122-147.

Tait, C. (2011-2012). The Chinese learner in the New Zealand university environment. New Zealand Annual Review of Education, 21, 165-183.

Tang, D.; Absalom, D. (1998). Teaching across cultures: Considerations for Western EFL teachers in China. Hong Kong Journal of Applied Linguistics, 3, 2, 117-132.

Tong, S. A. (2010). Lessons learned? School leadership and curriculum reform in Hong Kong. Asia Pacific Journal of Education, 30, 2, 231-241.

Volet, S. (1999). Learning across cultures: Appropriateness of knowledge transfer. International Journal of Educational Research, 31, 625-643.

Wang, X.; Chen, M. (2013). The questionnaire analysis research on the causes of college students' reticence in the English classroom. Comunicação apresentada em MDHSS 2013 - International Conference on the 
Modern Development of Humanities and Social Science, Hong Kong, dezembro de 2013. https://download. atlantis-press.com/article/10018.pdf.

Wong, E. (2015). Q. and A.: Michael Schuman on the return of Confucianism in China. The New York Times, 2 de abril. http://sonosphere.blogs.nytimes.com/2015/04/02/q-and-a-michael-schuman-on-the-returnof-confucionism-in-china-the-new-york-times.html.

Yu, T. (2008). The revival of Confucianism in Chinese schools: A historical-political review. Asia Pacific Journal of Education, 28, 2, 113-129.

Zhu, C.; Gao, Y. (2013). Communication with Chinese international students: Understanding Chinese international students' learning difficulties and communication barriers. Comunicação apresentada na British Educational Research Association Annual Conference, University of Manchester, Reino Unido, setembro de 2012. https://www.leeds.ac.uk/educol/documents/215282.pdf. 
